James G. Ramsay MD, Fiona E. Ralley MB CH B, David G. Whalley мв сн в, Peter DelliColli RRAT, J. Earl Wynands MD

\title{
Site of temperature monitoring and pre- diction of afterdrop after open heart surgery
}

To determine which of the commonly used "core" temperature sites, remote from the brain, best indicates total body rewarming, the temperatures in the rectum $(R T)$, urinary bladder (UBT) and the pulmonary artery (PAT) at the termination of cardiopulmonary bypass $(C P B)$ were correlated with the decrease in nasopharyngeal temperature (NPT) after CPB (afterdrop) in 29 patients. The amount of afterdrop is inversely related to the adequacy of total body rewarming, smaller values indicating better rewarming. All patients had uncomplicated cardiac surgery and received high pump flows during rewarming on $C P B$. The UBT showed the best correlation with afterdrop $(p<0.001)$ compared with the other temperature sites, the durations of $C P B$ and rewarming during $C P B$, and the time that the NPT was greater than $37^{\circ} \mathrm{C}$ during rewarming.

The urinary bladder is a simple, non-invasive monitoring site when a urinary catheter is required and our results indicated that the UBT is a better monitor of the adequacy of total body rewarming on CPB than NPT alone. The study also suggested that rewarming to a UBT in excess of $36.2^{\circ} \mathrm{C}$ prior to the termination of $C P B$ is unlikely to further reduce afterdrop.

\section{Key words}

TEMPERATURE: body rewarming; MONITORING: site of temperature probes; SURGERY: cardiovascular.

From the Department of Anaesthesia, Royal Victoria Hospital and McGill University, Montreal, Quebec. No reprints will be available.

Address correspondence to: Dr. J. Earl Wynands, Department of Anaesthesia, Royal Victoria Hospital, 587 Pine Avenue West, Montreal, Quebec H3A 1Al.

Supported by a grant from Oximetrix Inc.
It is common practice to use the nasopharyngeal temperature (NPT) as a monitor of brain temperature during cardiac surgery. When the NPT is used as an index of the adequacy of rewarming during cardiopulmonary bypass (CPB), this temperature usually decreases several degrees in the first hour after termination of CPB (afterdrop). Noback and Tinker were able to reduce afterdrop from $3^{\circ} \mathrm{C}$ to $2^{\circ} \mathrm{C}$ by maximising pump flows with vasodilators during rewarming. ${ }^{1}$ Using a similar technique and, in addition, heating and humidifying inspired gases after $\mathrm{CPB}$, we were unable to further reduce this afterdrop. ${ }^{2}$ Therefore it seems most likely that afterdrop is merely the revelation of inadequate total body rewarming on CPB. The brain receives a high proportion of the cardiac output relative to its weight and consequently it rewarms faster than the rest of the body. As the nasopharynx is said to reflect brain temperature, ${ }^{3}$ this suggests that the achievement of normothermia at this site does not accurately reflect the adequacy of total body rewarming.

We have found that the commonly used "core" temperature sites remote from the brain, such as the urinary bladder, rectum and the pulmonary artery lag behind the NPT during rewarming. These temperature sites have never been specifically assessed for their use as indices of total body rewarming on $\mathrm{CPB}$, and consequently we wished to determine which, if any, of these sites could best be used to predict afterdrop and therefore the adequacy of total body rewarming.

\section{Methods}

This study was performed with Ethics Committee approval, but as the conduct of the anaesthesia and surgery was no different than our normal practice, 
TABLE I Demographic data

\begin{tabular}{lllllll}
\hline & & & & & $\begin{array}{l}\text { Male: } \\
\text { female }\end{array}$ \\
ratio & Surgery \\
\hline Mean \pm SEM & Age $(\mathrm{yr})$ & Height $(\mathrm{cm})$ & Weigh $(\mathrm{kg})$ & $B S A\left(\mathrm{~m}^{2}\right)$ & ACBP* -22 \\
Range & $60.8 \pm 1.74$ & $170.90 \pm 1.80$ & $74.1 \pm 1.60$ & $1.86 \pm 0.03$ & $2.6: 1$ & Valve - \\
\hline
\end{tabular}

*Aortocoronary bypass.

informed consent was not obtained. Twenty-nine patients, 43-83 years old, undergoing uncomplicated valve replacement or aortocoronary bypass surgery were studied consecutively. Patients with symptomatic peripheral vascular disease, insulindependent diabetes, or body weight greater than 20 per cent above ideal body weight were excluded from the study. All patients were premedicated with diazepam $\left(0.15 \mathrm{mg} \cdot \mathrm{kg}^{-1}\right)$, morphine $\left(0.15 \mathrm{mg} \cdot \mathrm{kg}^{-1}\right)$ and scopolamine $\left(0.006 \mathrm{mg} \cdot \mathrm{kg}^{-1}\right)$. Prior to induction, and under local anaesthesia, an intravenous cannula, a radial artery cannula and a pulmonary artery catheter were inserted. Anaesthesia was induced with fentanyl $\left(40 \mu \mathrm{g} \cdot \mathrm{kg}^{-1}\right)$ plus pancuronium $\left(0.15 \mathrm{mg} \cdot \mathrm{kg}^{-1}\right)$ and maintained with 100 per cent oxygen and isoflurane as necessary. Temperatures were monitored using a Mon-a-Therm temperature monitor (Model 6000, Mon-a-Therm, Inc, St Louis, MO), which was self-calibrated at $25^{\circ} \mathrm{C}$ and $40^{\circ} \mathrm{C}$ before each study. Disposable temperature probes were inserted in the nasopharynx, the rectum and the urinary bladder (using a Mon-aTherm "Cath Temp" Foley catheter) and displayed on the temperature monitor. The temperature in the pulmonary artery was also recorded using the catheter thermistor and displayed on the cardiac output computer (Model 9520A, Edwards Laboratories, Santa Ana, CA). CPB was performed with a Sarns Model 7000 modular pump and Optiflow 11 or Bentley BOS-105 oxygenator and patients were cooled to $24-28^{\circ} \mathrm{C}$ NPT.

During rewarming on $\mathrm{CPB}$, maximal pump flows were obtained using isoflurane or an infusion of nitroglycerin. The water temperature in the heat exchanger of the heart-lung machine was maintained at a maximum of $10^{\circ} \mathrm{C}$ above NPT, but not exceeding $40^{\circ} \mathrm{C}$. Once the NPT was $37^{\circ} \mathrm{C}$ the water temperature was maintained at $38^{\circ} \mathrm{C}$ until the time at which the patients were weaned from $\mathrm{CPB}$, according to our normal criteria.

Temperatures at each site were recorded at the start of rewarming, every $10 \mathrm{~min}$ during rewarming, at the termination of $\mathrm{CPB}$, then at $10 \mathrm{~min}$ intervals for $1 \mathrm{hr}$ after $\mathrm{CPB}$, and thereafter at $30 \mathrm{~min}$ intervals for a further $3 \mathrm{hrs}$. The total time of CPB, the duration of rewarming on $\mathrm{CPB}$, and the time that the NPT was greater than $37^{\circ} \mathrm{C}$ before termination of CPB was also recorded.

Afterdrop was calculated as the difference between the NPT at the termination of CPB and the lowest NPT reached after CPB.

Mean values are presented with the standard error of the mean as an index of dispersion. Student's t test for unpaired data using Bonferroni's inequality for multiple comparisons was applied where appropriate and the null hypothesis rejected when $\mathrm{p}<0.05$. Nasopharyngeal temperature afterdrop was related to the temperature at all sites, at the

TABLE II Cardiopulmonary bypass data

\begin{tabular}{llll}
\hline & $B P T(\min )^{*}$ & $R W T(\min ) \dagger$ & $\begin{array}{l}N P T \geq 37^{\circ} \mathrm{C} \ddagger \\
(\min )\end{array}$ \\
\hline $\begin{array}{l}\text { Mean } \pm \text { SEM } \\
\text { Range }\end{array}$ & $\begin{array}{l}108.45 \pm 5.66 \\
(48-73)\end{array}$ & $\begin{array}{l}45.17 \pm 2.40 \\
(23-75)\end{array}$ & $\begin{array}{l}19.80 \pm 2.34 \\
(2-50)\end{array}$ \\
\hline
\end{tabular}

*Total cardiopulmonary bypass time.

†Rewarming time.

$\ddagger$ Time during rewarming on CPB when NPT $\geqslant 37^{\circ} \mathrm{C}$. 


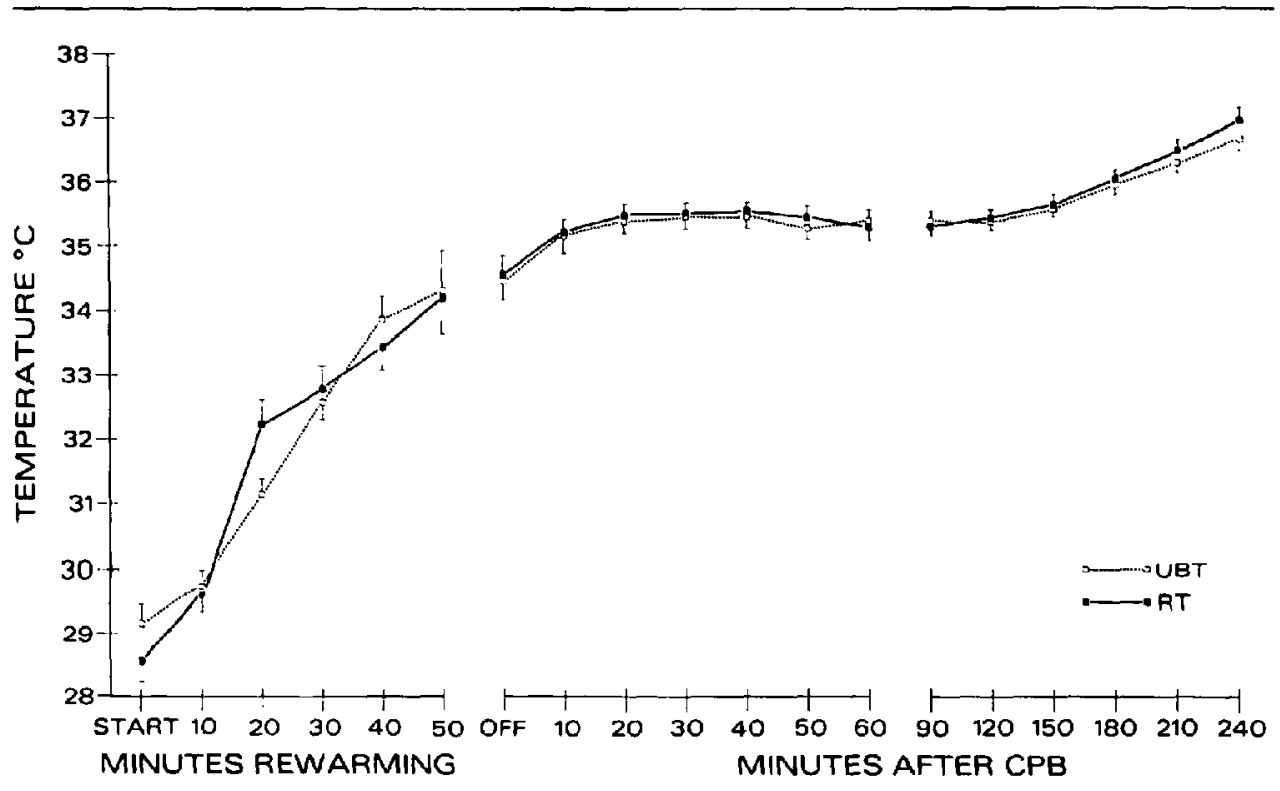

FIGURE 1 Urinary bladder temperature (UBT) and rectal temperature (RT) vs time in minutes from start of rewarming on cardiopulmonary bypass. "Start" is at start of rewarming on cardiopulmonary bypass (CPB) and "Off" is at the termination of CPB

termination of $\mathrm{CPB}$ and to the durations of $\mathrm{CPB}$ and rewarming during CPB using linear regression analysis. Polynomial equations up to the fifth power were applied to the analysis that showed the most significant correlation.

\section{Results}

The demographic data of the patients with the mean duration of $\mathrm{CPB}$, the duration of rewarming on $\mathrm{CPB}$, and the time that the NPT was greater than $37^{\circ} \mathrm{C}$ before termination of $\mathrm{CPB}$ are shown in Tables I and II. Figure 1 shows the mean UBT and mean RT recorded from the start of rewarming during CPB until the end of the study. Except at 20 minutes after the beginning of rewarming, no significant difference was demonstrated between the rectal (RT) and the urinary bladder temperature (UBT) for the duration of the study. For this reason and for the sake of clarity, however, only the UBT is shown in Figure 2 (the RT would follow a similar line as the UBT). The UBT and RT showed significant differences throughout rewarming when compared to both NPT and PAT. However, only after 20 mins from the start of rewarming is there a significant difference between the NPT and the PAT
(Figure 2). At the termination of $\mathrm{CPB}$ and at $10 \mathrm{~min}$ after CPB there are significant differences between the temperatures of all the sites monitored; the UBT being the coolest and the NPT the warmest (Figure 2). There continued to be a significant difference between the UBT and RT with the NPT at $20 \mathrm{~min}$ after CPB and between the NPT and the PAT at 30 min after CPB. By 40 min after $C P B$ and thereafter, there was no significant difference between the temperature at any site. There appears to be a trend for the PAT to be the lowest temperature of the sites monitored beyond $30 \mathrm{~min}$ after CPB.

The correlation coefficients of each of these temperature sites, the duration of CPB (BPT), the duration of rewarming on $\mathrm{CPB}$ (RWT) and the time at which the NPT was greater than $37^{\circ} \mathrm{C}$ during rewarming versus afterdrop are shown on Table III. Only the UBT $(R=0.61 ; \mathrm{p}<0.001$; Figure 3$)$ and the RT $(R=0.30 ; 0.02<p<0.05)$ showed significant correlation.

Figure 4 demonstrates the best fit polynomial equation (fourth order) to the data points relating UBT at termination of CPB to afterdrop. The nadir of the curve is at $36.25^{\circ} \mathrm{C}$ at which point the afterdrop is $2.01^{\circ} \mathrm{C}$. 

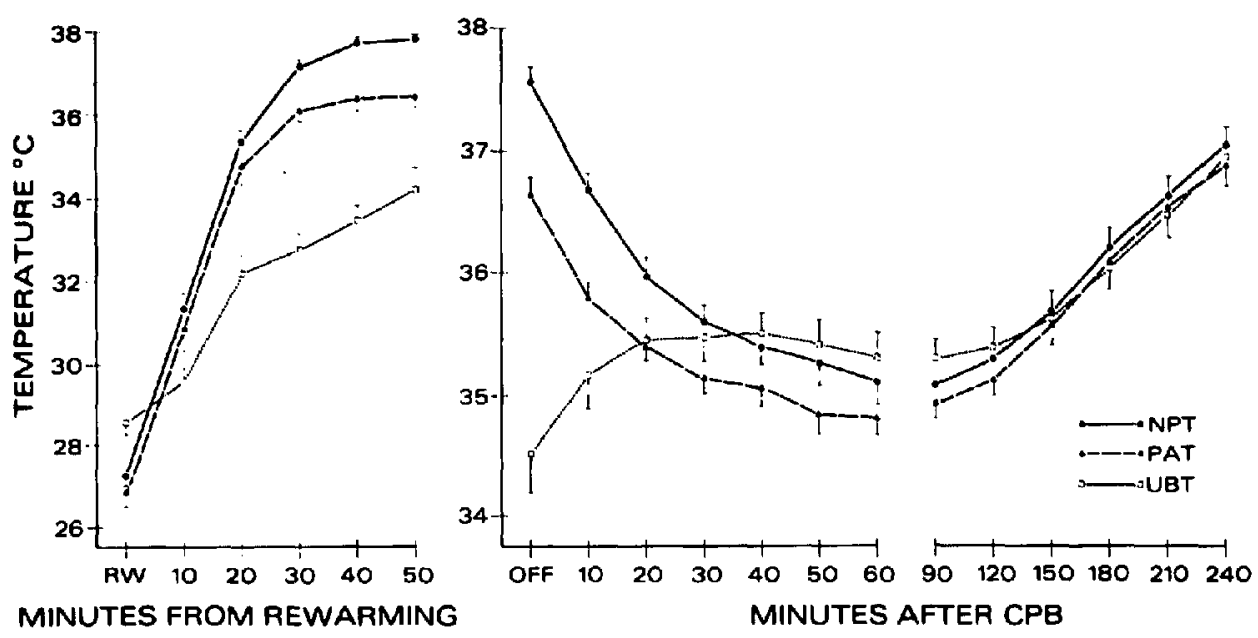

FIGURE 2 Nasopharyngeal temperature (NPT), pulmonary artery temperature (PAT) and urinary bladder temperature (UBT) vs time in minutes from the start of rewarming (RW) on cardiopulmonary bypass. "Off' is at termination of cardiopulmonary bypass. (Rectal temperature (RT) has been omitted for the sake of clarity as it followed the same line as the UBT.)

\section{Discussion}

Our results demonstrate that during rewarming, the UBT, RT and the PAT are slower to increase than the NPT, and that after the termination of CPB the UBT and RT were actually still increasing at a time when the NPT and PAT were decreasing (Figures 1 and 2). Davis et al. have shown that rewarming during CPB typically falls short of restoring the heat lost during cooling by almost 33 per cent, despite a normal NPT at the termination of CPB. ${ }^{4}$ They suggested that mainly muscle and subcutaneous fat remain cool despite normal core body temperatures.
While we did not compare the UBT nor the RT to the temperature in fat or muscle, both these temperature sites appear to reflect the cooler tissues as evidenced by their slower rewarming pattern during and after the termination of CPB.

Both the UBT and RT at termination of CPB showed significant correlation with afterdrop. However, this correlation just reached significance in the case of the RT $(0.02<\mathrm{p}<0.05)$, whereas it was highly significant in the case of the UBT ( $p<0.001$ ). Cork et al., when they compared the precision and accuracy of various temperature

TABLE III Correlation coefficients

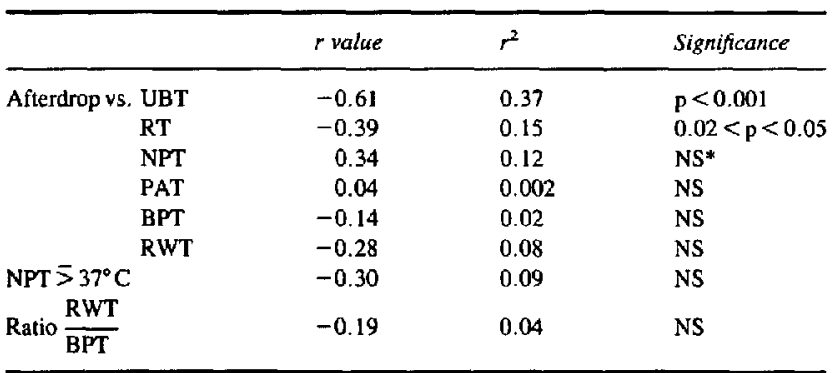

*NS-nat significant.

BPT-total time on CPB.

RWT-total time of rewarming on CPB. 


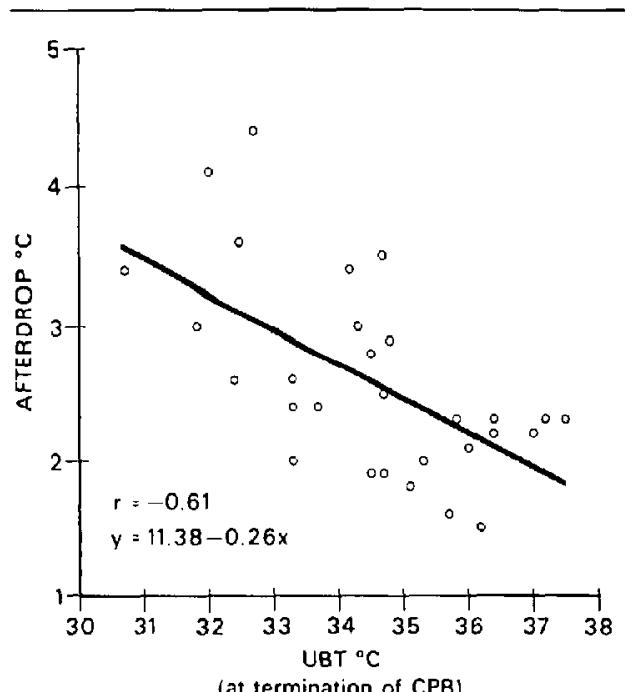

(at termination of $\mathrm{CPB}$ )

FIGURE 3 Linear regression line of "afterdrop" in " $\mathrm{C}$ vs urinary bladder temperature (UBT) in ${ }^{\circ} \mathrm{C}$ at termination of cardiopulmonary bypass (CPB). The correlation coefficient ( $r$ ) and the regression equation are as shown.

sites, ${ }^{5}$ showed that although the accuracy of these two temperature sensors is similar, the precision of the UBT probe exceeds that of the RT probe when compared with a tympanic membrane temperature (TMT) probe as the standard.

When the correlation coefficient ( $r$ ) for both of these temperature sites is squared, i.e., the coeffi-

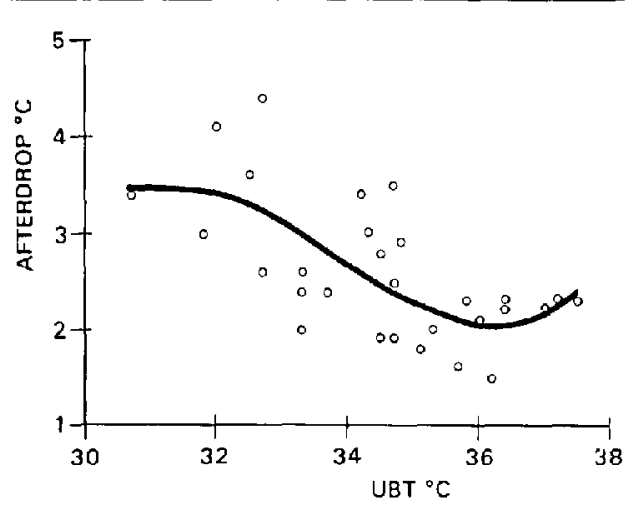

FIGURE 4 Best fit polynomial equation of "afterdrop" in " $\mathrm{C}$ vs urinary bladder temperature (UBT) at termination of cardiopulmonary bypass (CPB). cient of determination $\left(r^{2}\right)$, one can calculate the percentage of variance of the afterdrop (dependent variable) which can be predicted by variance in the UBT or RT respectively (independent variable). ${ }^{8}$ Therefore 36 and 16 per cent respectively (Table III) of the afterdrop can be predicted from the knowledge of these temperatures at termination of $\mathrm{CPB}$ (using the regression equation). This suggests that the RT is less reliable as a predictor of total body rewarming.

In addition, we favour the UBT rather than the RT for several practical reasons. Rectal probes may be easily dislodged during surgery and may be embedded in faeces, which are slower to respond, thus obtunding the rapid changes in temperature..$^{3,6}$ A urinary catheter is required in all patients undergoing cardiac surgery. The Mon-a-Therm $B$ catheter is a convenient, inexpensive monitor because it incorporates a thermocouple at its tip and adds just $\$ 5$ more to the cost of urinary catheterisation. ${ }^{7}$

When a polynomial, or best fit, curve is fitted to the data of UBT at the termination of CPB and afterdrop, the coefficient of determination is $\mathbf{0 . 6 2}$. Thus 62 per cent or the variance in afterdrop can be predicted by the variance in UBT at termination of CPB (Figure 4). Therefore the effectiveness of rewarming during $\mathrm{CPB}$, as reflected inversely by afterdrop must also be dependent on several other factors, not identified by this study, but probably related to the effects of anaesthesia and surgery on flows, perfusion pressures and vascular tone in fat and muscle.

Previous studies have shown that despite attempts to prevent the fall in NPT after the termination of CPB, with the use of vasodilators and/or heated, humidified gases, an afterdrop of at least $2^{\circ} \mathrm{C}$ can be expected. ${ }^{1,2}$ The nadir of the curve in Figure 4 corresponds to an afterdrop of approximately $2^{\circ} \mathrm{C}$, and our results suggest that afterdrop cannot be further reduced by rewarming to a UBT greater than $36^{\circ} \mathrm{C}$.

Although the differences do not reach statistical significance, there appears to be a trend for the PAT to be the coolest temperature site beyond 30 minutes after CPB. This may be due to the pulmonary artery receiving the venous return from the coolest parts of the body during the early phase of rewarming. By 90 minutes after CPB the mean temperatures at all sites were within $0.35^{\circ} \mathrm{C}$ of each other and consequently our data suggest that the choice of monitor- 
ing site thereafter could be made on the basis of convenience.

In summary, the results of this study indicated that the UBT was the best monitor of total body rewarming during CPB. We suggest that it is a useful complement to a monitor of NPT when a urinary catheter is required. There appears to be no amelioration of afterdrop when the patient is rewarmed to a UBT greater than $36^{\circ} \mathrm{C}$.

\section{References}

1 Noback $C R$, Tinker $J H$. Hypothermia after cardiopulmonary bypass in man; amelioration by nitroprusside-induced vasodilation during rewarming. Anesthesiology 1980; 53: 277-80.

2 Ralley FE, Ramsay JG, Wynands JE, Townsend GE, Whalley $D G$, Dellicolli $P$. Effects of heated, humidified gases on temperature drop after cardiopulmonary bypass. Anesth Analg 1984; 63: 1106-10.

3 Holdcroft A. Body temperature control in anaesthesia, surgery and intensive care. London: Bailliere Tindall, 1980: 55.

4 Davis FM, Parimelazhajan XN, Harris EA. Thermal balance during cariopulmonary bypass with moderate hypothermia in man. Br J Anaesth 1977; 49: 1127-32.

5 Cork RC, Vaughan RW, Humphreys LS. Precision and accuracy of intraoperative temperature monitoring. Anesth Analg 1983; 62: 211-14.

6 Blainey $C G$. Site selection in taking body temperature. Am J Nursing 1974; 74: 1859-61.

7 Lilly $J K$, Boland JP, Zekan S. Urinary bladder temperature monitoring: a new index of body core temperature. Crit Care Med 1980; 8: 742-4.

8 Kerlinger FN, Pedhazur EJ. Multiple regression in behavioral research. New York: Holt, Rinehart and Winston, Inc, 1973: 36.

\section{Résumé}

Afin de déterminer lequel des différents sites habituellement utilisés pour surveiller la température centrale représente le mieux le rechauffement corporel total; la température du rectum (RT). la vessie (UBT) et de l'artère pulmonaire (PAT) à la fin de CEC (CPB) ont été mis en corrélation avec la diminution de la temperature nasopharyngée (NPT) après CEC (afterdrop), chez 29 patients. Le degré de diminution de la température nasopharyngée (afterdrop) est inversement relié au degré de rechauffement corporel total; une faible valeur indiquant un meilleur rechauffement. Tous les patients ont subi une chirurgie cardiaque non compliquée et un réchauffement lors de la CEC obtenu avec une pompe à haut débit. La température de la vessie (UBT) a démontré une meilleur corrélation avec l'afterdrop $(p<0.001)$ comparativement aux autres sites de température, à la durée de la CEC el au rechauffement pendant la CEC ainsi qu'au temps ou la NPT était supérieure d $37^{\circ} \mathrm{C}$ lors du réchauffement.

La vessie représente un site de monitoring non-invasif quand un catheter urinaire est requis. Nos résultats indiquent que l'UBT est un site de surveillance de la température corporelle supérieur au NPT lors du réchauffement par CEC. L'étude aussi suggére que le réchauffement à une température vésicale supérieure à $36.2^{\circ} \mathrm{C}$ vers la fin de la CEC ne diminuera probablement pas l'afterdrop. 